\title{
Scale-dependent measurement and analysis of ground surface temperature variability in alpine terrain
}

\author{
S. Gubler ${ }^{1}$, J. Fiddes ${ }^{1}$, M. Keller ${ }^{2}$, and S. Gruber ${ }^{1}$ \\ ${ }^{1}$ Department of Geography, University of Zurich, Switzerland \\ ${ }^{2}$ Computer Engineering and Networks Laboratory, ETH Zurich, Switzerland \\ Received: 23 December 2010 - Published in The Cryosphere Discuss.: 25 January 2011 \\ Revised: 3 May 2011 - Accepted: 17 May 2011 - Published: 25 May 2011
}

\begin{abstract}
Measurements of environmental variables are often used to validate and calibrate physically-based models. Depending on their application, the models are used at different scales, ranging from few meters to tens of kilometers. Environmental variables can vary strongly within the grid cells of these models. Validating a model with a single measurement is therefore delicate and susceptible to induce bias in further model applications.

To address the question of uncertainty associated with scale in permafrost models, we present data of 390 spatially-distributed ground surface temperature measurements recorded in terrain of high topographic variability in the Swiss Alps. We illustrate a way to program, deploy and refind a large number of measurement devices efficiently, and present a strategy to reduce data loss reported in earlier studies. Data after the first year of deployment is presented.

The measurements represent the variability of ground surface temperatures at two different scales ranging from few meters to some kilometers. On the coarser scale, the dependence of mean annual ground surface temperature on elevation, slope, aspect and ground cover type is modelled with a multiple linear regression model. Sampled mean annual ground surface temperatures vary from $-4^{\circ} \mathrm{C}$ to $5^{\circ} \mathrm{C}$ within an area of approximately $16 \mathrm{~km}^{2}$ subject to elevational differences of approximately $1000 \mathrm{~m}$. The measurements also indicate that mean annual ground surface temperatures vary up to $6^{\circ} \mathrm{C}$ (i.e., from $-2^{\circ} \mathrm{C}$ to $4{ }^{\circ} \mathrm{C}$ ) even within an elevational band of $300 \mathrm{~m}$. Furthermore, fine-scale variations can be high (up to $2.5^{\circ} \mathrm{C}$ ) at distances of less than $14 \mathrm{~m}$ in homogeneous terrain. The effect of this high variability of an environmental variable on model validation and applications in alpine regions is discussed.
\end{abstract}

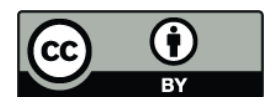

Correspondence to: S. Gubler stefanie.gubler@geo.uzh.ch

\section{Introduction}

The combination of environmental monitoring and modeling plays an important role when investigating current and future climate and their control of diverse phenomena of the cryosphere. Measurements are widely used for model validation and calibration. However, the problem of comparing model simulations made at one scale to measurements taken at another scale has no simple solution. The relevance of this issue increases when modeling phenomena such as snow cover or permafrost in highly variable terrain such as the Swiss Alps, since variations occur at smaller scales than in more homogeneous terrain. The difficulties that arise from scaling issues can be large: in contrast to measurements, spatially-distributed models are often grid-based and represent areas of several square meters to square kilometers. Since the physical processes that influence the pattern of variation of a phenomena operate and interact at different spatial scales, spatial variation can simultaneously occur on scales of different orders of magnitude (Oliver and Webster, 1986). Therefore, the extrapolation of results (including calibrated model outputs) based on point measurements requires caution, especially in highly variable terrain (Nelson et al., 1998). A specific statement concerning this issue was made by Gupta et al. (2005):
A less obvious source of error is when the variable predicted by a model is not the same quantity as that measured (even though they might be referred to by the same name) because of scale effects, non- linearities or measurement technique problems.

Due to the lack of spatially-distributed measurements, the influence of the scaling problem on model validation has barely been investigated earlier.

The study of permafrost in mountain regions has become important in view of ongoing climate change (Harris et al., 2009; Gruber and Haeberli, 2007). Alpine environments are

Published by Copernicus Publications on behalf of the European Geosciences Union. 
characterized by variable topography, influencing slope, aspect, elevation, ground properties, snow distribution and the energy fluxes at the Earth's surface. Ground surface temperatures thus vary over short distances and permafrost, while integrating over larger surface areas in depth, is strongly affected by this topographic variability. Diverse permafrost studies have been performed in alpine regions in the last decades; ranging from long-term monitoring projects such as Permafrost Monitoring Switzerland (PERMOS: www. permos.ch), over measurement campaigns of bottom temperature of snow (BTS) (Haeberli, 1973; Hoelzle et al., 2003) and ground surface temperatures (GST) (Gruber et al., 2004a; Hoelzle and Gruber, 2008) to statistical and physically based modeling (Haeberli, 1975; Stocker-Mittaz et al., 2002; Gruber, 2005; Nötzli et al., 2007). While measuring ground temperatures (GT) is costly, GST and BTS measurements usually require much less resources. Distributed measurement of GST and BTS at fine scales is therefore feasible, however measurements at the surface are strongly affected by topographic and ground cover variations. Since GST is strongly coupled to air temperature, it depends, in a first approximation, on altitude. However, GST is also strongly influenced by topography through snow redistribution, exposition to the sun, shading from surrounding terrain and ground properties. Snow cover exerts an important influence on the ground thermal regime based on differing processes (Keller and Gubler, 1993; Zhang, 2005; Luetschg et al., 2008). On gently inclined Alpine slopes, snow cover mostly causes a net increase of mean annual ground surface temperatures (MAGST) due to its insulating effect during winter, but the timing and thickness of first snow cover, mean snow cover thickness as well as the timing of melt-out strongly control the local magnitude of this effect and are subject to strong inter-annual variation (Hoelzle et al., 2003; Brenning et al., 2005). Near-surface material can also affect GST and induce a large lateral variability of GST over just tens of meters. Especially for large block material, a lowering of MAGST has been observed and can be attributed to the circulation of cold air during winter (Haeberli, 1973; Harris, 1996; Juliussen and Humlum, 2008; Gorbunov et al., 2004) as well as purely conductive effects that do not require ventilation (Gruber and Hoelzle, 2008). Furthermore, the exposition to solar radiation has a strong effect on the energy budget at a specific point. The amount of radiation received at a point depends on slope angle, the exposure to the sun and shading from surrounding terrain. The difference in GST between two sides of an east-west oriented ridge can be more than $5^{\circ} \mathrm{C}$ (Gruber et al., 2004b; PERMOS, 2010).

The following questions are addressed in this paper:

- How can we efficiently obtain a spatially-distributed and dense set of measurements, that represent the diverse sources of variability that operate on different spatial and temporal scales?

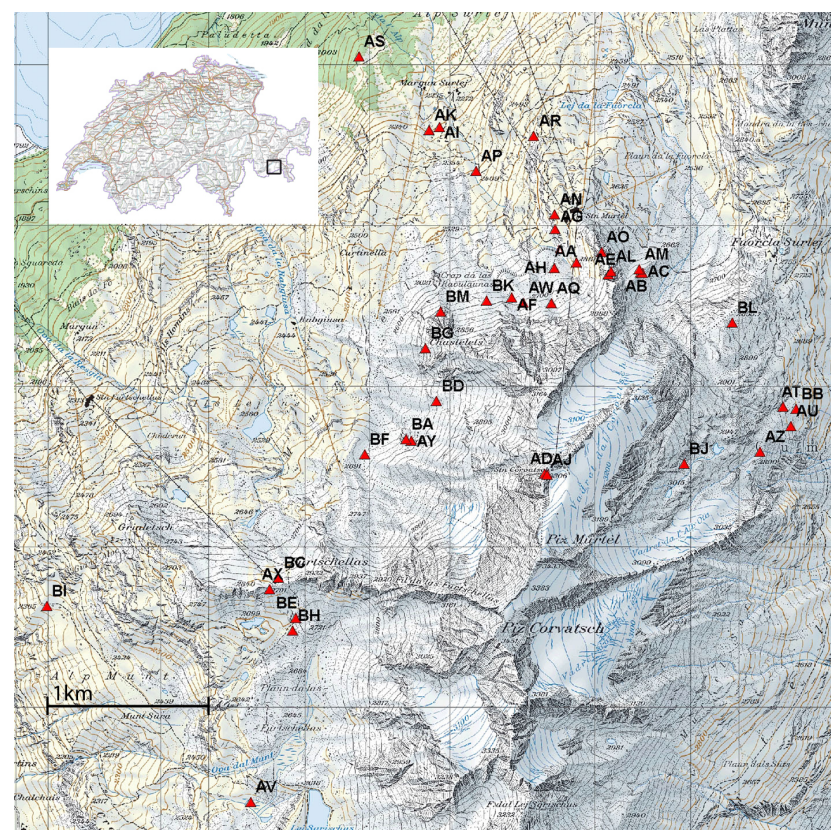

Fig. 1. Locations of the 39 footprints at Corvatsch study site. Reproduced by permission of swisstopo (BA110077).

- How do topographic parameters and ground cover types influence MAGST in an area of several square kilometers?

- What is the variation of ground surface temperatures within a $10 \mathrm{~m} \times 10 \mathrm{~m}$ field?

- What uncertainty is associated with scaling between point measurements and gridded models?

\section{Instruments and methods}

\subsection{Study site}

The study site of Corvatsch lies in the eastern part of the Swiss Alps $\left(46.42^{\circ}\right.$ N/9.82 ${ }^{\circ}$ E, Fig. 1$)$. Several rock glaciers and some small glaciers exist around Piz Corvatsch, and the area has a long tradition of cryosphere research (Hoelzle et al., 2002). A cable car facilitates the access to the area. Elevation ranges from approximately $1900 \mathrm{~m}$ to $3300 \mathrm{~m}$ a.s.l. Precipitation reaches mean values of $800 \mathrm{~mm}$ in the valley floors and $1000 \mathrm{~mm}$ to $2000 \mathrm{~mm}$ in the valley side belts (Schwarb et al., 2000). The zero degree isotherm of the mean annual air temperature (MAAT) is at $2200 \mathrm{~m}$ a.s.l. Meteorological data are measured by MeteoSwiss at Piz Corvatsch ( $3315 \mathrm{~m}$ a.s.l.) in the center of the study area. 


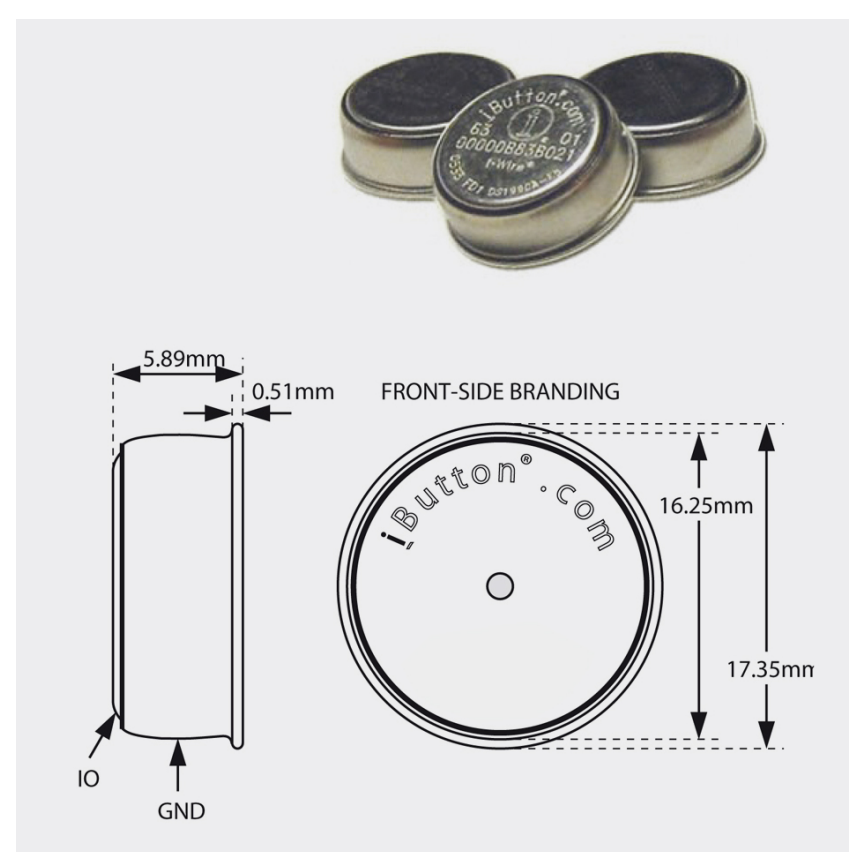

Fig. 2. The iButton ${ }^{\circledR}$ DS1922L that was used for temperature measurements.

\subsection{Instruments}

The iButton ${ }^{\circledR}$ DS1922L (Fig. 2) is a coin-sized, commercial device that integrates a micro-controller, $8 \mathrm{kB}$ storage, a realtime clock, a temperature sensor, and a battery in a single package. The iButton measures temperatures from $-40^{\circ} \mathrm{C}$ to $85^{\circ} \mathrm{C}$ with $\pm 0.5^{\circ} \mathrm{C}$ accuracy from $-10^{\circ} \mathrm{C}$ to $65^{\circ} \mathrm{C}$. At that resolution, it can store 4096 readings in memory.

Lewkowicz (2008) states that about $13 \%$ of the iButtons that were deployed to monitor the snow-pack in Northern Canada failed, most probably due to water entry. To avoid this, iButtons were waterproofed by sealing them in pouches of $40 \mathrm{~mm} \times 100 \mathrm{~mm}$ in the present study. The material is a $140 \mu \mathrm{m}$ thick laminate (oriented polyamide, polyethylene and aluminium) designed to withstand long periods of wetness as well as intense solar radiation without significant deterioration. Since the iButtons are buried into the ground, the pouches have no influence on the measured GST. Using a portable impulse tong sealer (polystar $300 \mathrm{~A}$ ) operated with $12 \mathrm{~V}$ batteries, these pouches can be re-sealed in the field after cutting the seal and reading out the iButton data.

A campaign with hundreds of devices (almost 400 in this study) asks for as much automation as possible, and generates a large amount of data that must be handled properly. For this, the iAssist management tool (Keller et al., 2010) was developed to deploy, localize and maintain the iButton data loggers. A relational database is used to store measurements and meta data, i.e., GPS coordinates and pictures.

\subsection{Experiment design}

The amount of samples required to adequately resolve the spatial patterns of the phenomena of interest increases with their heterogeneity (cf., Nelson et al., 1998). In order to resolve the spatial patterns and the variability of GST around Corvatsch, 39 locations, so-called footprints, were selected such that most of the topographic variability within this area of approximately $16 \mathrm{~km}^{2}$ is represented (Fig. 1). On the one hand, the focus in footprint selection lay on the influence of the topographic variables elevation, slope and aspect, and additionally ground cover types and terrain curvature. On the other hand, the replication of GST measurements within each $10 \mathrm{~m} \times 10 \mathrm{~m}$ footprint reflects the variability in GST at a fine scale. Each footprint is chosen to be as homogeneous as possible with respect to aspect, slope and surface cover.

To represent GST variability due to slope, aspect and ground material, one main elevational band was selected for intense instrumentation. It ranges from $2600 \mathrm{~m}$ to $2900 \mathrm{~m}$ a.s.l. Some footprints lie outside this band and reflect the dependence of GST on elevation. The footprints cover all aspects, steep and gentle slopes and different ground cover types such as meadow, fine material and large blocks (Table 1). Aspect, slope, elevation and terrain curvature were estimated from a digital elevation model (DEM) of $25 \mathrm{~m}$ resolution.

Note that slopes larger than $50^{\circ}$ are not sampled in this study. The ground cover type (GCT) is differentiated in four groups: GCT1 represents near-surface material with a high amount of fine, and often also organic material. GCT3 stands for entirely block-covered areas, GCT2 lies in between. GCT4 consists of all footprints that do not fit into GCT1 to GCT3, i.e. indicating either meadows covered with small to medium size blocks, or ridges consisting of rock and large boulders. Shading from surrounding terrain plays a major role in determining the amount of solar radiation reaching the ground. At each footprint, the local horizon was recorded using a digital camera (Nikon Coolpix 990) with a fish eye converter (Nikon FC-E8) (Gruber et al., 2003). These pictures permit to determine the sky view factor at each footprint. Snow depth and snow water equivalent were measured three times during winter, in January, mid March and end of April 2010. Due to avalanche danger, snow data only exists for some footprints.

\subsection{Logger placement}

In order to record near-surface temperatures and avoid heating by direct solar radiation, the iButtons were buried approximately $5 \mathrm{~cm}$ into the ground or placed between and underneath boulders. GST is measured every $3 \mathrm{~h}$ at $0.0625^{\circ} \mathrm{C}$ resolution, enabling operation for 512 days. The data recording always started at midnight. Within each $10 \mathrm{~m} \times 10 \mathrm{~m}$ footprint, we randomly distributed ten iButtons (Fig. 3). The one hundred square meters were numbered, and a uniform sample of size 10 was generated with R (R Development Core Team, 2011), determining the ten squares to place the 
Table 1. Meta data of footprints. $B_{k}$ denotes the number of valid iButton measurements at footprint $k$. MAGST of footprint $k$ is denoted by $\mu_{k}$ (Eq. 1) and the variability of MAGST is $\xi_{k}$ (Eq. 2). Coordinates are given in the Swiss coordinate system CH1903. Elevation, slope and aspect are derived from a DEM with $25 \mathrm{~m}$ resolution. Slope is given in degrees, as well as aspect counting from the north clockwise. GCT stands for ground cover type and classifies the footprints into four groups: group one is fine material often including organic material, group three is very coarse material such as the large boulders on the rock glaciers, and group two lies in between. Group four contains all footprints consisting of heterogeneous ground cover, partially including bedrock. Note that both footprints AL and AO are separated into two groups. Within AL, half of the iButtons lie in slightly concave terrain (AL2), the rest in convex terrain (AL1) on a ridge. Due to this difference which influences snow accumulation, AL1 and AL2 are treated as two different footprints. Similarly within AO: the ten iButtons are located on both sides of a steep $\mathrm{N}-\mathrm{S}$ ridge, i.e., five iButtons are north-east exposed (AO1), five are south-west exposed (AO2).

\begin{tabular}{|c|c|c|c|c|c|c|c|c|c|}
\hline Footprint & $\mathrm{x}$-coord & $y$-coord & $B_{k}$ & Elev. & Slope & Aspect & GCT & $\mu_{k}$ & $\xi_{k}$ \\
\hline AA & 783292 & 144769 & 10 & 2694 & 38 & 251 & 1 & 3.82 & 0.59 \\
\hline $\mathrm{AB}$ & 783691 & 144709 & 10 & 2745 & 16 & 96 & 2 & 2.96 & 1.33 \\
\hline $\mathrm{AC}$ & 783701 & 144704 & 10 & 2743 & 31 & 112 & 2 & 4.34 & 1.15 \\
\hline $\mathrm{AD}$ & 783092 & 143454 & 10 & 3303 & 29 & 263 & 4 & -3.65 & 1.69 \\
\hline $\mathrm{AE}$ & 783490 & 144696 & 10 & 2826 & 29 & 290 & 1 & 0.89 & 1.88 \\
\hline $\mathrm{AF}$ & 782888 & 144552 & 10 & 2689 & 23 & 9 & 4 & -1.62 & 2.12 \\
\hline AG & 783159 & 144979 & 9 & 2664 & 48 & 243 & 4 & 2.29 & 2.52 \\
\hline $\mathrm{AH}$ & 783151 & 144735 & 10 & 2663 & 9 & 318 & 3 & -0.55 & 1.10 \\
\hline AI & 782437 & 145612 & 7 & 2307 & 18 & 330 & 1 & 3.17 & 0.36 \\
\hline $\mathrm{AJ}$ & 783108 & 143449 & 10 & 3302 & 27 & 113 & 4 & -1.56 & 2.22 \\
\hline AL1 & 783506 & 144714 & 5 & 2824 & 14 & 347 & 1 & 1.00 & 0.22 \\
\hline AL2 & 783506 & 144714 & 5 & 2824 & 25 & 60 & 1 & 1.53 & 0.16 \\
\hline AM & 783682 & 144727 & 10 & 2738 & 30 & 333 & 2 & 0.52 & 0.87 \\
\hline AN & 783155 & 145070 & 9 & 2673 & 2. & 252 & 1 & 3.24 & 0.27 \\
\hline AO1 & 783446 & 144834 & 5 & 2811 & 3 & 64 & 4 & -1.43 & 1.72 \\
\hline $\mathrm{AO} 2$ & 783446 & 144834 & 5 & 2811 & 18 & 238 & 4 & 1.41 & 0.60 \\
\hline $\mathrm{AP}$ & 782667 & 145339 & 5 & 2405 & 15 & 335 & 1 & 2.56 & 0.45 \\
\hline $\mathrm{AQ}$ & 783135 & 144517 & 10 & 2729 & 29 & 12 & 3 & -1.04 & 1.06 \\
\hline $\mathrm{AR}$ & 783026 & 145559 & 7 & 2528 & 28 & 288 & 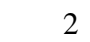 & 2.91 & 0.25 \\
\hline AS & 781936 & 146051 & 8 & 2100 & 35 & 315 & 1 & 4.89 & 1.09 \\
\hline AT & 784575 & 143872 & 10 & 2790 & 36 & 100 & 1 & 3.52 & 1.00 \\
\hline $\mathrm{AU}$ & 784625 & 143751 & 10 & 2773 & 33 & 88 & 3 & 1.67 & 0.55 \\
\hline $\mathrm{AV}$ & 781263 & 141412 & 10 & 2538 & 0 & 212 & 1 & 3.59 & 0.16 \\
\hline AW & 782960 & 144519 & 9 & 2700 & 19 & 333 & 3 & -2.01 & 0.63 \\
\hline $\mathrm{AX}$ & 781380 & 142736 & 10 & 2810 & 23 & 135 & 1 & 3.55 & 1.03 \\
\hline $\mathrm{AY}$ & 782264 & 143661 & 10 & 2687 & 9 & 328 & 2 & 2.12 & 0.8 \\
\hline $\mathrm{AZ}$ & 784433 & 143592 & 10 & 2876 & 7 & 61 & 1 & 2.41 & 0.28 \\
\hline BA & 782231 & 143669 & 10 & 2697 & 27 & 111 & 1 & 3.60 & 0.44 \\
\hline BB & 784659 & 143858 & 10 & 2763 & 14 & 103 & 1 & 3.06 & 0.45 \\
\hline BC & 781437 & 142806 & 8 & 2783 & 41 & 357 & 2 & -1.24 & 1.00 \\
\hline BD & 782420 & 143906 & 10 & 2705 & 27 & 247 & 0 & 3.56 & 0.81 \\
\hline $\mathrm{BE}$ & 781543 & 142558 & 9 & 2710 & 29 & 167 & 1 & 3.98 & 0.73 \\
\hline $\mathrm{BF}$ & 781972 & 143576 & 10 & 2645 & 5 & 31 & 1 & 2.43 & 0.65 \\
\hline BG & 782351 & 144237 & 10 & 2715 & 43 & 246 & 1 & 3.56 & 2.14 \\
\hline BH & 781525 & 142480 & 10 & 2693 & 6 & 243 & 3 & 1.42 & 2.47 \\
\hline BI & 779993 & 142631 & 4 & 2362 & 24 & 192 & 1 & 5.42 & 0.36 \\
\hline BJ & 783961 & 143517 & 10 & 2997 & 36 & 90 & 2 & 1.46 & 1.24 \\
\hline BK & 782731 & & 9 & 2691 & 31 & 355 & 2 & 1.69 & 0.46 \\
\hline BL & 783962 & 143526 & 10 & 2875 & 19 & 35 & 3 & 0.21 & 1.01 \\
\hline BM & 782444 & 144464 & 10 & 2715 & 44 & 314 & 4 & -1.49 & 2.26 \\
\hline
\end{tabular}

iButtons. This random placement reduces systematic bias in the measurements due to subjectivity.

Each iButton was fixed to a yellow string to facilitate refinding. To prevent iButtons from falling down steep slopes, log- gers were attached to large, stable boulders. At each footprint, a wooden stick was stamped into the ground, marking one vertex of the $10 \mathrm{~m} \times 10 \mathrm{~m}$ square. Two blue ropes were then attached to the stick identifying the local grid. 

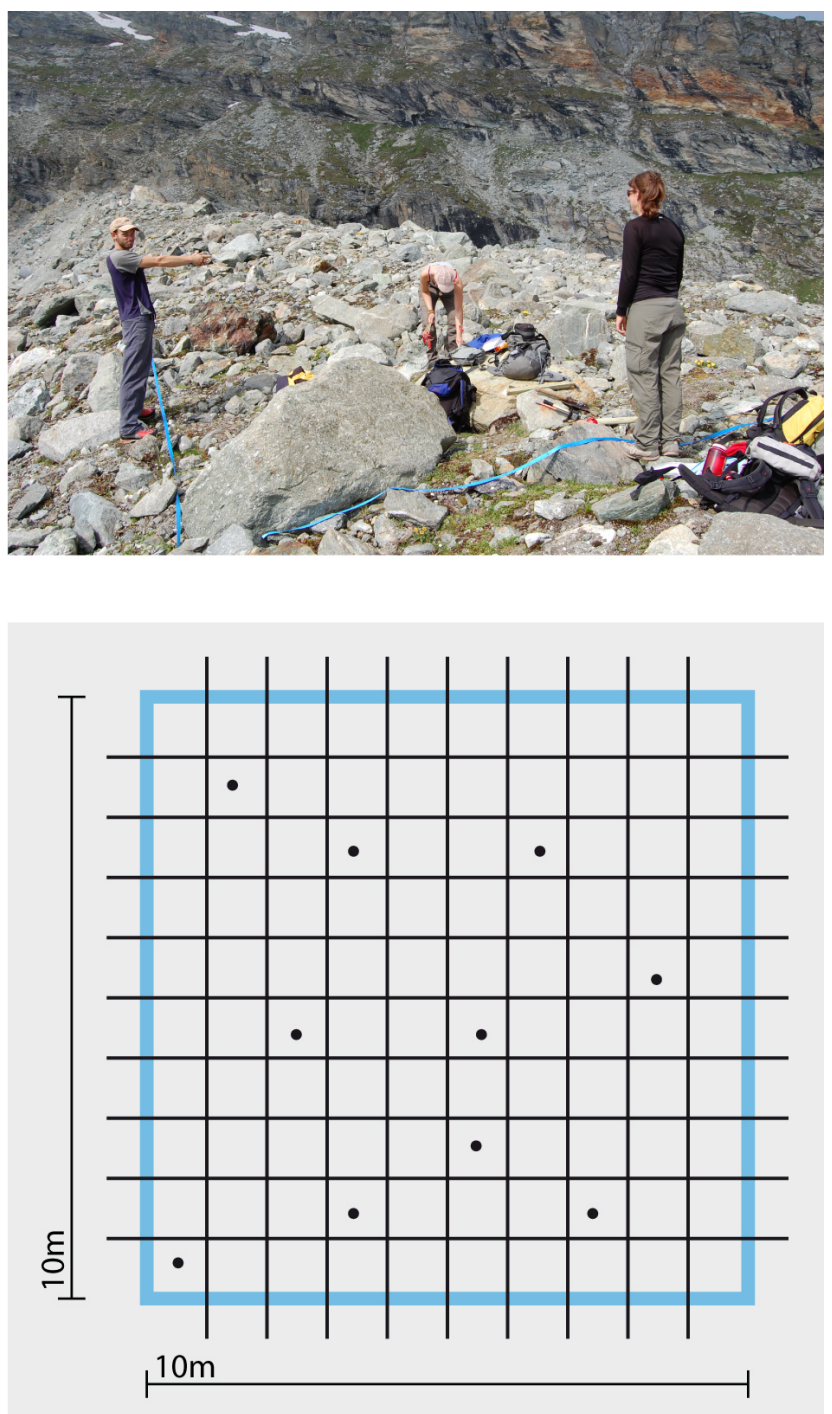

Fig. 3. Ten iButtons were randomly distributed in each $10 \mathrm{~m} \times 10 \mathrm{~m}$ footprint. One vertex of the square was marked with a stick. Two ropes representing two orthogonal edges were attached to the stick. The blue ropes served as rulers. The local grid and the sampled numbers were manually recorded.

The iButtons were distributed in two field campaigns. Therefore, the two groups AA to AS (17 July 2009 to 16 July 2010, period 1) and AT to BM (14 August 2009 to 13 August 2010, period 2) cover slightly different time periods.

\subsection{Data analysis}

The main focus of the data analysis is the variability of MAGST at the two scales investigated. At the coarse scale $\left(16 \mathrm{~km}^{2}\right)$, we analyse the variability (the so-called interfootprint variability) of the mean MAGST $\mu_{k}$, which at footprint $k$ is defined as the mean of the mean of each time series within that footprint, i.e.:

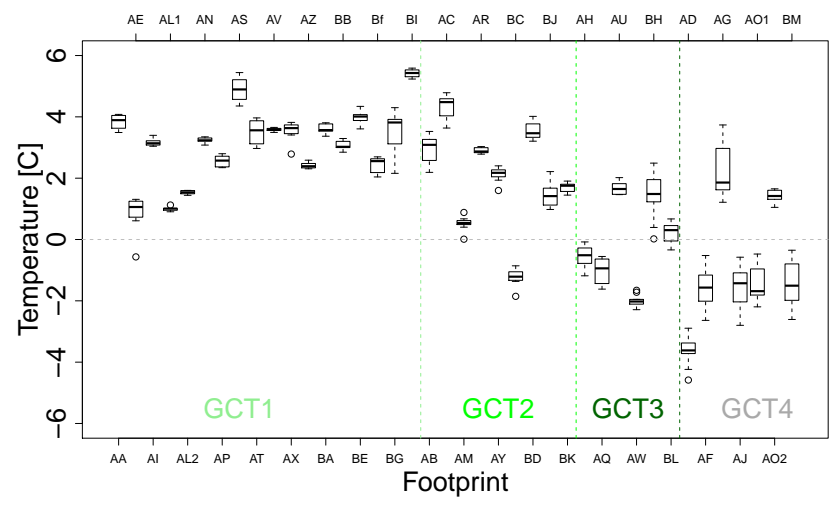

Fig. 4. Boxplots of MAGST of all iButtons at the footprints. The footprints are ordered according to the ground cover types, the vertical dashed lines separate the four GCT groups from each other.

$\mu_{k}:=\frac{1}{B_{k}} \sum_{i=1}^{B_{k}} \mu_{k, i}$

Here, $B_{k}$ is the number of iButtons at footprint $k$, and $\mu_{k, i}$ denotes MAGST of iButton $i$ at footprint $k$. The distribution of the $\mu_{k, i}$ for all footprints is presented in Fig. 4. The intrafootprint variability $\xi_{k}$ of MAGST at footprint $k$, which is used to study the variability at the fine scale $\left(100 \mathrm{~m}^{2}\right)$, is defined as the range of the MAGST of all iButtons within that footprint:

$\xi_{k}:=\max _{i=1, \cdots, B_{k}}\left(\mu_{k, i}\right)-\min _{i=1, \cdots, B_{k}}\left(\mu_{k, i}\right)$.

To quantify the influence of the topographic variables on $\mu_{k}$ and $\xi_{k}$, a multiple linear regression analysis is performed.

\section{Results}

\subsection{General description}

In Fig. 5, ground surface temperatures of four different footprints are presented. GST vary strongly between different footprints, depending on elevation, exposition to the sun and conditions of snow. The two footprints on the top station of Corvatsch, $\mathrm{AD}$ and $\mathrm{AJ}$, are highly correlated to air temperature, even in winter (Fig. 5). They are wind-exposed and thick snow is unlikely to accumulate. AJ, which is oriented to the east, shows bigger daily temperature amplitudes and is two degrees warmer than AD, which is west-exposed. Since clouds often develop in the afternoon, the west exposed footprint $\mathrm{AD}$ receives less direct solar radiation.

The footprints $\mathrm{BC}$ and $\mathrm{AX}$ are snow-covered during winter. Daily temperature variations cease in the beginning of October, when the first large snow fall event of winter 2009/2010 occurred. At BC, a steep north-oriented slope, temperature damping by snow is observed some weeks later than at AX. 
AD

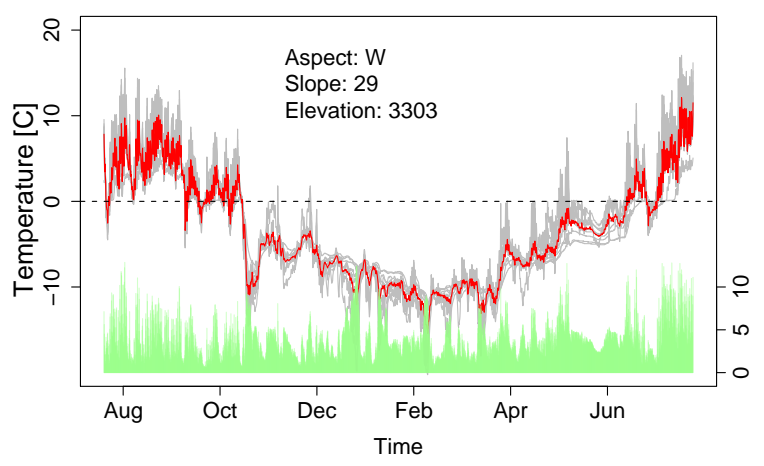

AJ

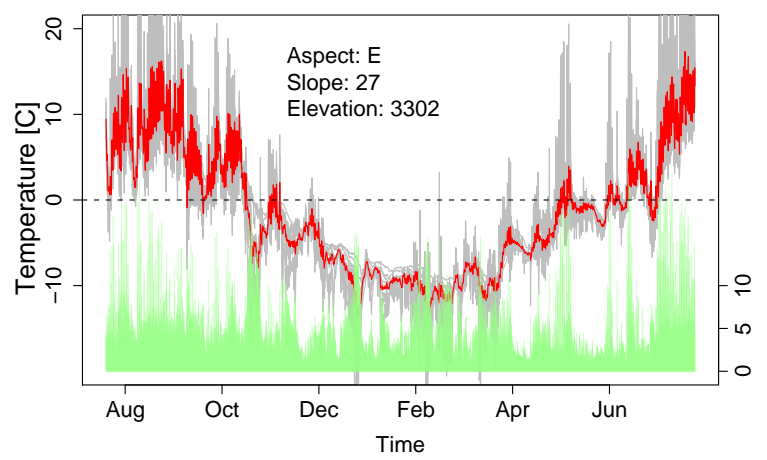

AX

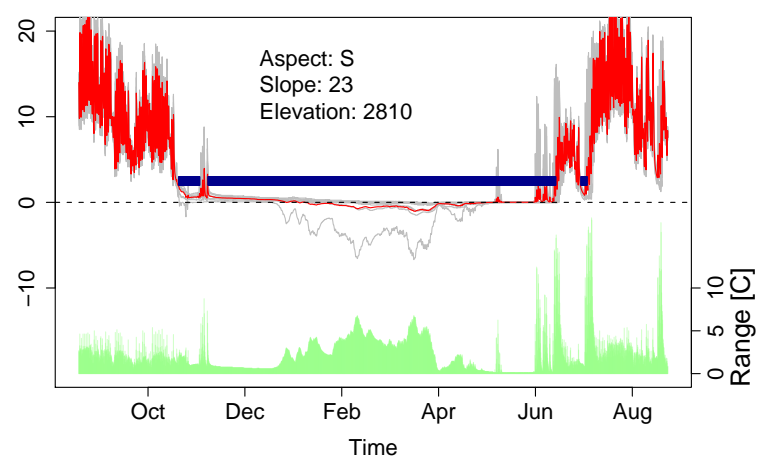

BC

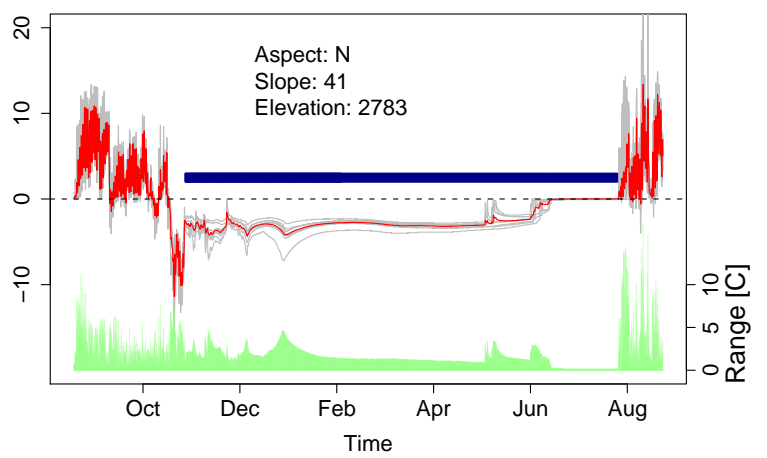

Fig. 5. GST of footprints AD, AJ, AX and BC. The grey lines in the background plot a maximum of ten iButtons located at the footprints. The red line indicates the mean GST at each time step. At the bottom of each plot, the range of all iButtons is plotted, indicating the temperature variability within each footprint. Snow cover is indicated in blue and was estimated manually based on daily temperature variations (Danby and Hik, 2007). Zero curtains can be identified at the end of the snow periods at AX and BC.

In late spring, the snow cover at $\mathrm{BC}$ lasts much longer. Since the slope is north exposed, it receives limited solar radiation, and therefore snow melting occurs much slower than at the nearby, south-oriented slope AX. The difference in MAGST between $\mathrm{AX}$ and $\mathrm{BC}$ is more than $4{ }^{\circ} \mathrm{C}$. At AX, GST in summer is much higher than at $\mathrm{BC}$, and thus the combined effect of warming due to solar radiation at $\mathrm{AX}$ and cooling due to long lasting snow in late spring at $\mathrm{BC}$ are responsible for this large difference. The snow depths measurements confirm that at both $\mathrm{BC}$ and $\mathrm{AX}$ a homogeneous snow cover isolated the ground from the cold winter air temperatures, in comparison to $\mathrm{AJ}$ and $\mathrm{AD}$, where only small snow patches of several centimeter depths were observed.

Similar effects can be observed at diverse other footprints, for example at BA and AY. They lie close together (i.e., less than $30 \mathrm{~m}$ distance), however AY is in a zone with high snow accumulation. Melting takes more time, and snow cover in AY lasts approximately one month longer than at BA, resulting in a $1.5^{\circ} \mathrm{C}$ lower MAGST (Table 1 ).

\subsection{Data quality}

The techniques developed to protect, manage, distribute and refind many data loggers have proven to be effective. In order to refind the buttons, mainly the yellow strings and the local grids were of great help, resulting in the recovery of 367 out of 390 iButtons after the first year.

Every retrieved iButton recorded valid data, indicating the importance of the pouches used when compared to $13 \%$ loss reported previously (Lewkowicz, 2008). However, some iButtons reappeared on the surface (i.e., the measurements are disturbed by the direct solar radiation) and were excluded from the analysis. In total, $93 \%$ of the iButtons recorded data that could be used for the analysis.

A zero curtain, i.e., the effect of latent heat due to freezing or thawing, results in stable temperatures near $0^{\circ} \mathrm{C}$ over extended time periods. Zero curtains were detected at several footprints (for example at the end of the snow season in both $\mathrm{AX}$ and BC, Fig. 5) and serve, in this study, to analyse the accuracy of the measurement devices. The zero curtains at each individual iButton were detected in a first step by using a threshold of the temperature deviation from zero degrees. Varying the threshold from $0.0625^{\circ} \mathrm{C}$ to $0.25^{\circ} \mathrm{C}$ in steps of 
$0.0625^{\circ} \mathrm{C}$ indicated that variations of zero curtain periods within even very homogeneous footprints are large for the smallest threshold. When choosing a threshold of $0.125^{\circ} \mathrm{C}$, detected zero curtain periods become homogeneous. Choosing the larger two thresholds does not have a big influence on the detected zero curtain periods. This vicarious calibration indicates that the iButtons measure temperatures at an accuracy of $\pm 0.125^{\circ} \mathrm{C}$ (i.e. two digital numbers) near zero degrees.

\subsection{Inter-footprint variability}

Measured MAGST varies from $-3.65^{\circ} \mathrm{C}$ to $5.42{ }^{\circ} \mathrm{C}$ around Corvatsch (Table 1). This variation can, to a large degree, be explained with the topographic variability. In order to quantify the influence of the topographic variables, a multiple linear regression model was fitted to the data using ordinary least squares. The full model contained the explanatory variables elevation, slope, aspect, ground cover type, sky view factor and curvature. An iterative, step-wise model reduction according to the Akaike-Information-Criteria (Akaike, 1973) combined with the addition of higher polynomials and interaction terms led to the model shown in Eq. (3). Note that sine and cosine of the aspect are taken to ensure continuity. Since aspect is recorded from the north clockwise, cosine represents the dependence on north-south differences, and west-east differences are represented by the sine.

$$
\begin{aligned}
\mu_{\mathrm{k}}= & 17.63-0.0056 \cdot \text { Elevation }_{k} \\
& -0.48 \cdot \cos \left(\text { Aspect }_{k}\right) \\
& +0.42 \cdot \sin \left(\text { Aspect }_{k}\right) \\
& +0.0056 \cdot \text { Slope }_{k} \\
& +0.22 \cdot \mathrm{dGCT}_{k, 2} \\
& -1.66 \cdot \mathrm{dGCT}_{k, 3} \\
& -2.2 \cdot \mathrm{dGCT}_{k, 4} \\
& -0.057 \cdot\left(\text { Slope }_{\mathrm{k}}: \cos \left(\text { Aspect }_{\mathrm{k}}\right)\right) \\
& +\varepsilon_{k} .
\end{aligned}
$$

MAGST plotted against elevation is shown in Fig. 6. Additionally, the fitted values of Model (3) are plotted. The model explains $93 \%$ of the MAGST variability (Fig. 7), the adjusted $R^{2}$ equals $91 \%$ and the model is highly significant $\left(p<10^{-14}\right.$, where $p$ is the $\mathrm{p}$-value). The model coefficients and their interpretation are explained in Sect. 4.1 in more detail. Note that GCT is a categorical variable and is therefore represented through the dummy variable dGCT (i.e., $\mathrm{dGCT}_{k, 2}=1$ if and only if footprint $k$ is of ground cover type 2 , else $\mathrm{dGCT}_{k, 2}=0$ ). Consequently, the different ground cover types influence the intercept of the linear regression. The random variables $\varepsilon_{k}$ are independent and normally distributed with zero mean and constant variance. Residual analysis did not show any strong deviations from this model assumptions. The spatial autocorrelation was studied by estimating the semivariogram of the residuals, showing that the

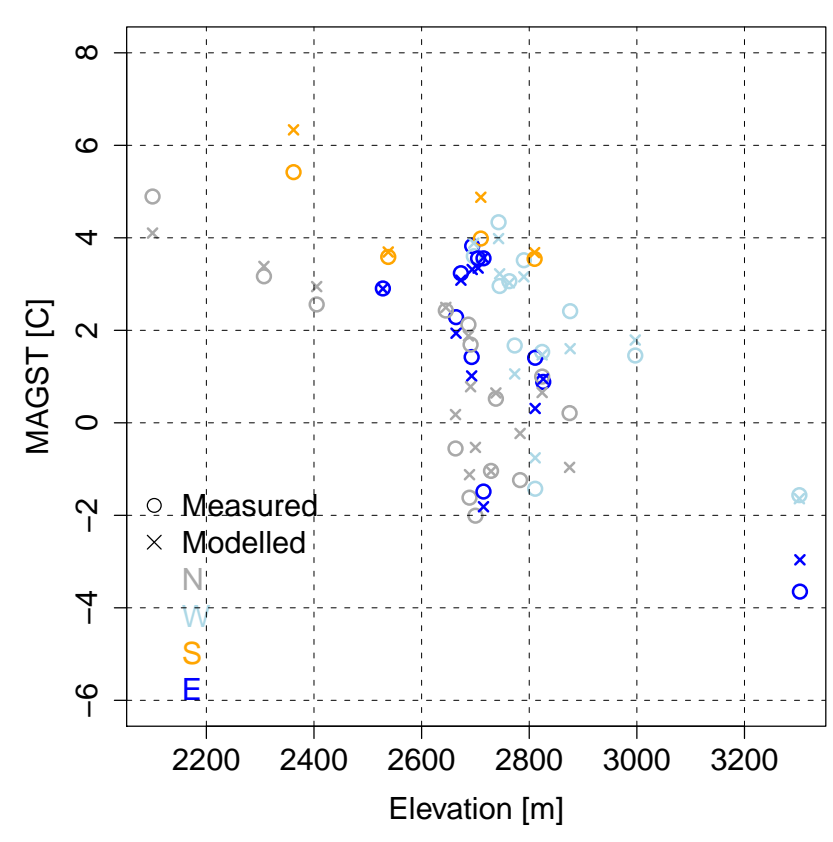

Fig. 6. MAGST of all footprints plotted against elevation. Colors identify the different aspects. Measured MAGST are indicated with a circle, the crosses denote the fitted values from the linear model shown in Eq. (3).

residuals are spatially not autocorrelated. This supports the statement by Nelson et al. (1998), who concluded that the variability due to the high variations in topography at small to medium distances dominates over spatial structures. The confidence interval of a coefficient contains all values that would not be rejected by the t-test at a previously specified significance level, i.e., it indicates the uncertainty associated with the coefficient. The $95 \%$ confidence intervals of Model (3) are presented in Table 2. Some confidence intervals are rather large, since the data sample is relatively small (forty values fitted to four explanatory variables). Model uncertainty is smallest at the data center. All variables except for three differ significantly from zero. The exceptions are $\mathrm{dGCT}_{2}$ which, as part of a dummy variable, is not separable from the highly significant $\mathrm{dGCT}_{3}$, and $\cos$ (Aspect) and Slope, which are kept in the model since their interaction is significant.

10-fold cross-validation has been performed to estimate the model behaviour. Thereby, one of ten randomly selected subsets serves as validation data, and the remaining nine as training data. The residuals at each point in the validation data are estimated, and the procedure is repeated until each subset exactly once served as validation data. The mean of the residuals of the 39 footprints resulted in $-0.03^{\circ} \mathrm{C}$ with standard deviation $0.78^{\circ} \mathrm{C}$. The root mean squared error was $0.77^{\circ} \mathrm{C}$. Further, the influence of the difference in summer temperatures of the two time periods 1 and 2 on the results of the regression analysis was analysed. MAAT differs by 


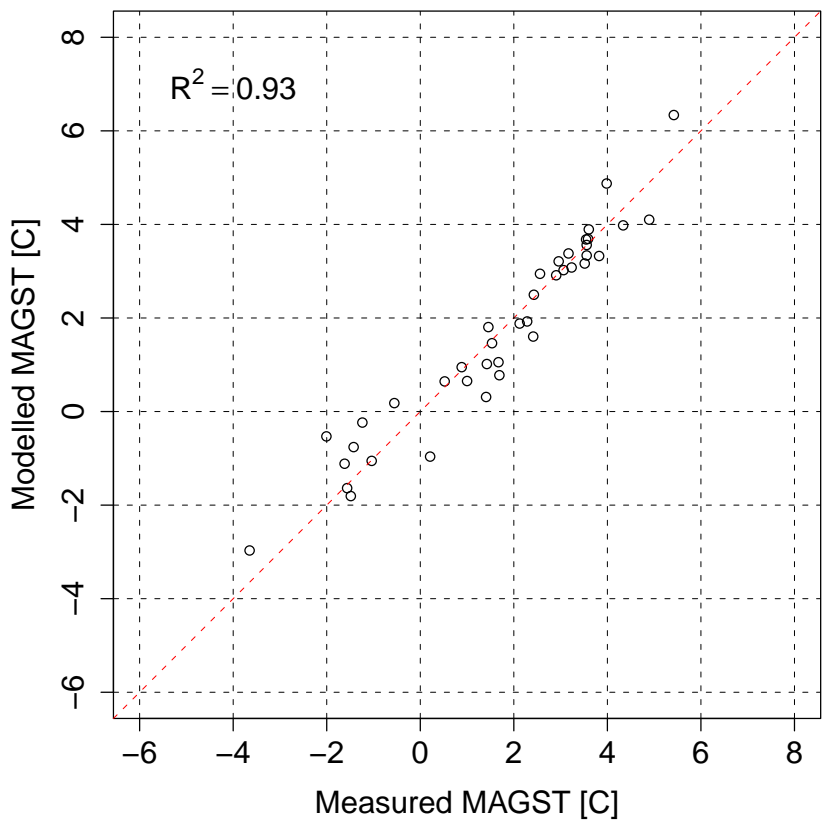

Fig. 7. Scatterplot of measured and modelled MAGST of Model (3). The dashed red line indicates the diagonal $y=x$. The model explains $93 \%$ of the variability of measured MAGST.

Table 2. $95 \%$ confidence intervals of the inter-footprint analysis coefficients (Model (3)).

\begin{tabular}{lrr}
\hline Coefficient & $2.5 \%$ & $97.5 \%$ \\
\hline Intercept & 14.24 & 21.04 \\
Elevation & -0.0068 & -0.0043 \\
cos(Aspect) & -1.23 & 0.27 \\
sin(Aspect) & 0.11 & 0.72 \\
Slope & -0.01 & 0.03 \\
dGCT $_{2}$ & -0.38 & 0.82 \\
dGCT $_{3}$ & -2.34 & -0.98 \\
dGCT $_{4}$ & -2.94 & -1.47 \\
Slope:cos(Aspect) & -0.086 & -0.027 \\
\hline
\end{tabular}

approximately $0.16{ }^{\circ} \mathrm{C}$ between the two periods. To analyse the influence of this difference in MAAT, Model (3) was fitted to the mean of the GST measurements of the overlapping time period (14 August 2009 to 16 July 2010) instead of the $\mu_{k}$. The only difference observed between the two analyses is a negative shift of the intercept of approximately $0.8^{\circ} \mathrm{C}$, resulting from the absent summer temperatures between the 17 July and the 13 August of the respective years. This indicates that air temperature has an effect on absolute, but not on relative MAGST, and that sign and order of magnitude of the influence of the topographic variables on MAGST are representative for that year.
Table 3. $95 \%$ confidence intervals of the intra-footprint analysis coefficients (Model (4)).

\begin{tabular}{lrr}
\hline Coefficient & $2.5 \%$ & $97.5 \%$ \\
\hline Intercept & -1.7 & -8.56 \\
Slope $^{2}$ & 0.0004 & 0.001 \\
dGCT $_{2}$ & 0.093 & 1.88 \\
dGCT $_{3}$ & 0.83 & 2.49 \\
dGCT $_{4}$ & 0.47 & 2.3 \\
Slope $^{2}: \mathrm{dGCT}_{2}$ & -0.0018 & $7.86 \cdot 10^{-5}$ \\
Slope $^{2}: \mathrm{dGCT}_{3}$ & -0.003 & $-4.77 \cdot 10^{-4}$ \\
Slope $^{2}: \mathrm{dGCT}_{4}$ & -0.001 & $2.38 \cdot 10^{-4}$ \\
\hline
\end{tabular}

\subsection{Intra-footprint variability}

Variability in MAGST varies strongly between the different footprints. It ranges from $0.16^{\circ} \mathrm{C}$ at the very homogeneous footprint $\mathrm{AV}$ to almost $2.5^{\circ} \mathrm{C}$ at $\mathrm{BH}$ (Table 1). Variation is generally larger for coarser ground material and more heterogeneous ground cover (Fig. 4). Similarly as before, we modelled the dependence of the variation on the topographic variables. The final model is:

$$
\begin{aligned}
\log \left(\xi_{k}\right)= & -1.28+0.0009 \cdot \mathrm{Slope}_{k}^{2} \\
& +0.98 \cdot \mathrm{dGCT}_{k, 2} \\
& +1.66 \cdot \mathrm{dGCT}_{k, 3} \\
& +1.38 \cdot \mathrm{dGCT}_{k, 4} \\
& -0.0009 \cdot\left(\operatorname{Slope}_{k}^{2}: \mathrm{dGCT}_{k, 2}\right) \\
& -0.0018 \cdot\left(\operatorname{Slope}_{k}^{2}: \mathrm{dGCT}_{k, 3}\right) \\
& -0.0006 \cdot\left(\operatorname{Slope}_{k}^{2}: \mathrm{dGCT}_{k, 4}\right) \\
& +\varepsilon_{k} .
\end{aligned}
$$

Again, model assumptions are not violated and the residuals are spatially not autocorrelated. The model explains $58 \%$ of the total variability in the range, the adjusted $R^{2}$ equals $49 \%$. The model is significant $\left(p<10^{-4}\right)$. The confidence intervals of the linear model are shown in Table 3.

\section{Discussion}

\subsection{Inter-footprint variability}

While our measurements have a high reliability due to their spatial density, their temporal support of only one full year needs to be kept in mind. As previous studies have demonstrated, considerable inter-annual variability of ground temperatures (Isaksen et al., 2002; Hoelzle et al., 2003; Gruber et al., 2004a; Brenning et al., 2005; Etzelmüller et al., 2007; Hipp et al., 2011) depending especially on snow conditions, absolute values need to be interpreted with caution. 


\subsubsection{Elevation and temperature lapse rate}

MAGST decreases with a lapse rate of $-5.6^{\circ} \mathrm{C} \mathrm{km}^{-1}$. While this overall value lies within the range of MAAT lapse rates reported for the Alps by Rolland (2002) and MAGST lapse rates of $-4^{\circ} \mathrm{C} \mathrm{km}^{-1}$ to $-7^{\circ} \mathrm{C} \mathrm{km}^{-1}$ found in the literature (Powell et al., 1988; Šafanda, 1999), it should not indicate that ground temperature gradients are exclusively tied to those of the air. The complex coupling between atmosphere and subsurface can results in markedly differing lapse rates depending on ground type, topography and snow cover.

\subsubsection{Aspect, slope and incoming solar radiation}

Exposition to the sun has a large influence, resulting in a difference of $1{ }^{\circ} \mathrm{C}$ between north and south facing slopes, if the slopes are rather gentle. Steep slopes however show a much larger variations between north and south, resulting in differences of $2^{\circ} \mathrm{C}$ for $10^{\circ}$ steep slopes, and up to $5^{\circ} \mathrm{C}$ for $40^{\circ}$ steep slopes, which can be seen in the interaction term Slope : $\cos$ (Aspect) in Eq. 3. This clearly shows the influence of the incoming solar radiation on GSTs, since northern exposed, steep slopes receive almost no direct solar radiation (especially in winter time), in contrast to more gentle slopes. South-exposed slopes show an opposite behaviour: depending on the angle of the incoming solar radiation (and thus the season), steeper slopes receive more radiation and accumulate less snow than gentle slopes, resulting in faster snow melting and thus warming of the ground in spring. This increased difference in MAGST for north-south variations for steep slopes is in accordance with the findings for steep rock (cf., Gruber et al., 2004b; PERMOS, 2010). East exposed slopes are approximately $0.8^{\circ} \mathrm{C}$ warmer than west exposed slopes, which can possibly be attributed to the formation of convective clouds during afternoons. Since the interaction of slope and the sine of aspect is not significant, the coefficient of the sine is interpreted as a mean difference between all west- and east-exposed slopes.

\subsubsection{Slope and snow}

The re-distribution of snow by avalanches, which results in higher snow depths at the rather gentle slopes, would result in a cooling of gentle slopes in late spring, as it is suggested by the model for south-facing slopes (a $40^{\circ}$ steep slope is predicted to be around around $2{ }^{\circ} \mathrm{C}$ warmer than a $10^{\circ}$ slope on a south face). At north-exposed slopes, the contrast is predicted (the steeper slope is around $1.5^{\circ} \mathrm{C}$ colder than the gentle slope). This may be mainly explained with solar radiation (see above). However, the interactions between snow cover and ground surface temperatures are complex. A thick snow cover in early winter insulates the ground from cold air temperatures. On the other hand, a thin snow cover can cool the ground during winter due to the high albedo of snow. Through modeling experiments, Bartlett et al. (2004) have shown that especially the timing and the duration of the snow cover have a large, non-linear influence on MAGST, and that snow cover can produce both a cooling and a warming of the GST in respect to the air temperature.

Wind plays an important role determining snow depths and snow water equivalent (Föhn and Meister, 1983). The influence of wind on the snow distribution is strongly determined by terrain parameters, such as slope, aspect and curvature. However, since curvature does not significantly determine MAGST in Model (3), and since the influence of slope and aspect are already discussed above, the influence of wind on MAGST is not discussed separately.

\subsubsection{Ground cover type}

The influence of near-surface material on MAGST detected in this study (around $1.6^{\circ} \mathrm{C}$ smaller in large blocks than at meadow sites) is supported by the findings of Hoelzle et al. (2003) and Gruber and Hoelzle (2008) for the Alps. Higher differences of around $4{ }^{\circ} \mathrm{C}$ to $7^{\circ} \mathrm{C}$ of MAGST between blocky material and finer-grained soils were found by Harris (1996) and Harris et al. (1998) in Kunlun Shan, China, and the Rocky mountains, Canada. This effect can be attributed to various processes (Gruber and Hoelzle, 2008), such as the ventilation of cold air below the snow cover on block fields or contrasts in thermal conductivity. Furthermore, moisture and water content encountered in the upper layer of the ground play a crucial role for GSTs. Temperatures in moisture-rich ground drop less quickly due to the energy release during the phase change from water to ice. On the other hand, a lot of energy is needed in spring time to melt ice contained in the ground. In contrast to the negative coefficient of dGCT3, the coefficient for dGCT2 is positive. Since this coefficient is not significantly different from zero on one hand, and its value is small, this is not further interpreted. Similarly, we do not treat the coefficient of dGCT4, since GCT4 consists of all ground cover types that could not be classified properly into the three classes.

\subsection{Intra-footprint variability}

The variability of MAGST was defined as the range of the MAGST at one footprint. We found that MAGST can vary from $0.2^{\circ} \mathrm{C}$ up to $2.5^{\circ} \mathrm{C}$ within $100 \mathrm{~m}^{2}$. The variability is larger at footprints with large boulders and in steep terrain (Model (4)). These fine-scale variations can be attributed to differing ground properties, water availability, heterogeneous snow cover, solar radiation and local shading of small to medium boulders, etc. However, the variability is small in homogeneous grass sites. Within large blocks, logger placement probably also has an effect on intra-footprint variability due to the difficulty of defining the surface. Snow distribution affects MAGST variability strongly, and is likely to be more variable at steep slopes and in rough terrain. Model (4) indicates that especially in blocky material and 
in steep slopes, a measurement might not represent its surrounding convincingly, and that the replication of a measurement would yield important additional information.

This result and the outcomes of Sect. 4.1 support the importance of the statement made by Gupta et al. (2005). When modeling permafrost conditions and comparing the outputs to a (point) measurement, we should keep in mind that the measurement only to a certain degree represents its surroundings. This not only applies for GSTs, but also at greater depths: even though temperatures integrate over larger surface areas and are thus not that susceptible to changes at the surface, ground temperatures might still vary considerably within some meters of distance. The uncertainty in measurements due to fine-scale variations can influence the outputs of permafrost models of any order of complexity; such as statistical models which are often based on and fitted to BTS or GST measurements (Haeberli, 1973; Keller, 1992; Boeckli et al., 2011) on one hand, and also more physically-based models used to estimate ground temperatures, active layer thicknesses and permafrost evolution (Zhang et al., 2003; Gruber et al., 2004a; Heggem et al., 2006; Nötzli et al., 2007; Farbrot et al., 2007; Etzelmüller et al., 2011; Hipp et al., 2011), which are often fitted to measurements of a few boreholes and extrapolated in space and time.

\subsection{Findings in relation to previous works}

Many studies addressing GST, GT and BTS variability due to solar radiation, snow cover, humidity, vegetation, etc. have been performed at diverse locations all over the world (Ishikiwa and Hirakawa, 2000; Heggem et al., 2006; Bonnaventure and Lewkowicz, 2008), and recently, even below the tree line (Lewkowicz and Bonnaventure, 2011). In this section, the findings discussed in Sect. 4.1 are related to similar studies concerning GST and BTS measurements.

As we have seen, measured MAGST varies up to $9{ }^{\circ} \mathrm{C}$ in an area of approximately $16 \mathrm{~km}^{2}$. However, elevation only explains $33 \%$ of the variability in MAGST. We can observe in Fig. 6 that MAGST varies more than $6^{\circ} \mathrm{C}$ within one elevational band ( $2600 \mathrm{~m}$ to $2900 \mathrm{~m}$ ). A similar pattern has been found by Etzelmüller et al. (2007, Fig. 4a) in Iceland, where MAGST varies around $6{ }^{\circ} \mathrm{C}$ within $800 \mathrm{~m}$ a.s.l. to $1000 \mathrm{~m}$ a.s.l. Since these measurements cover three years, this variability was mainly attributed to differing snow cover. However, the scatter within one year can also be attributed to the topographic variability, supporting the findings made in this study. In contrast to the small correlation with elevation found in this study and by Gruber and Hoelzle (2001), where elevation explained $31 \%$ of the variability of BTS measurements performed in the upper Matter Valley, Switzerland, Isaksen et al. (2002) analysed hundreds of BTS measurements in Southern Norway and found a high correlation of $91 \%$. The high correlation by Isaksen et al. (2002) was attained through a grouping of the BTS measurements following Hoelzle (1992), in contrast to the correlations of around
$60 \%$ reached before the grouping. The relationship to aspect or potential incoming solar radiation was estimated to be very low (Isaksen et al., 2002), the analysis is however reported to be not representative due to missing measurements towards south and west exposed slopes. Further, Hauck et al. (2004) estimated high correlations of MAGST with elevation (more than 90\%), but attribute this to the fact that the measurements are placed along an altitudinal transect, but do not differ much in aspect or slope.

In the context of previous works, the findings presented in this study demonstrate:

a. The importance of the systematic approach when distributing the measurement devices to capture the influence of the topographic variables. The coefficients estimated by the multiple regression Model 3 are reasonable, the model captures the influence of the topography quite well. For further analyses, the approach could even be expanded by for example integrating more samples of GCT3.

b. Simple regression analyses are not able to capture the influence of diverse predictors on a predictand, in contrast to multiple regression. In this study, correlation of MAGST with the cosine of the aspect reaches only $24 \%$, and correlations with the sine are even less than $1 \%$. Concluding that the topographic variables do not satisfyingly describe MAGST would be easy, since correlations to elevation (33\%) and slope (less than 1\%) are also small. Multiple linear regression allowed to include the dummy variable GCT, and further accounts for interactions and non-linearities, resulting in a robust model enabling new insight.

\section{Conclusions}

The use of iButtons to intensively measure spatiallydistributed GST was successful and pouches have shown to be very important. iButtons measure temperature with an accuracy of $\pm 0.125^{\circ} \mathrm{C}$. The experiment design was useful to both investigate the dependence of MAGST on topography, and to study fine scale variability of MAGST.

The use of multiple linear regression has shown that MAGST variability can be explained with the topographic variables elevation, slope, aspect and ground cover type. The model shows that MAGST are $1.6^{\circ} \mathrm{C}$ to $2.2^{\circ} \mathrm{C}$ higher in soil than within coarse blocks. South-exposed slopes are in general warmer than north facing slopes, however the difference changes with slope angle. East-exposed slopes are around $0.8^{\circ} \mathrm{C}$ warmer than west-exposed slopes. The terrain curvature and the sky view factor have no significant influence on MAGST in this model. Over the whole study area, measured MAGST variations go up to $9{ }^{\circ} \mathrm{C}$.

MAGST vary also at very fine scales: even in homogeneous areas, variations amount to more than $2.5^{\circ} \mathrm{C}$ at distances of 
less than $\approx 14 \mathrm{~m}$ at steep slopes or in terrain of large blocks. This is one fourth of the variation encountered over the whole study area, and is similar to the modelled north-south differences of $15^{\circ}$ slopes.

This study indicates that validation and calibration of gridbased models using measurements has to be performed with caution. The question of representativeness of a measurement location for its surroundings is often unclear. Since environmental variables vary strongly at even very fine scales, model validation and calibration with measurements of these variables can strongly be biased. Repeated measuring at different scales allows to estimate the natural variability of a variable, and thereby to improve model validation.

\section{Data availability}

The measurements, the meta data and the source code of the presented statistical analyses are published as supplementary material. The data is ordered according to the footprint names (i.e., all measurements taken at footprint AA are found in the file data_AA.csv). Each file contains the temperature measurements of all iButtons that were placed within that footprint together with the time stamps. The file Footprint_Metadata.csv contains the meta data shown in Table 1 plus sky view factor and different curvature indices. Additionally, a horizon file of each footprint is given (called hor_AA.txt for footprint AA). The second column in the horizon file indicates the elevation of the surrounding terrain above the horizon in direction of the azimuth given in the first column. The file src_ibutton.r contains the R-code. The two files meta.csv and meta_coord.csv are used as input to the code.

\section{Supplementary material related to this article is available online at: http://www.the-cryosphere.net/5/431/2011/ tc-5-431-2011-supplement.zip.}

Acknowledgements. The authors are grateful for the support given by the Corvatschbahnen, the developers of iAssist Guido Hungerbühler, Oliver Knecht and Suhel Sheikh, as well as Vanessa Wirz, Marlene Scheel, Christina Lauper and MarcOlivier Schmid and everybody else who helped to distribute and refind the iButtons. The constructive comments given by the two referees B. Etzelmüller and I. Berthling are greatly acknowledged. This project was funded by the Swiss National Science Foundation (SNSF) via the NCCR MICS project PermaSense and the project CRYOSUB (Mountain Cryosphere Subgrid Parameterization and Computation, 200021_121868). All statistical analyses were performed with R (www.cran.r-project.org).

Edited by: T. Zhang

\section{References}

Akaike, H.: A new look at the statistical model identification, IEEE Trans. Autom. Control, 19, 716-723, 1973.

Bartlett, M. G., Chapman, D. S., and Harris, R. N.: Snow and the ground temperature record of climate change, J. Geophys. Res., 109, F04008, doi:10.1029/2004JF000224, 2004.

Boeckli, L., Brenning, A., Gruber, S., and Noetzli, J.: A statistical permafrost distribution model for the European Alps, The Cryosphere Discuss., 5, 1419-1459, doi:10.5194/tcd-5-14192011, 2011.

Bonnaventure, P. B. and Lewkowicz, A. G.: Mountain permafrost probability mapping using the BTS method in two climatically dissimilar locations, northwest Canada, Can. J. Earth Sci., 45, 443-455, 2008.

Brenning, A., Gruber, S., and Hoelzle, M.: Sampling and statistical analyses of BTS measurements, Permafrost Periglac., 16, 383 393, 2005.

Danby, R. K. and Hik, D. S.: Responses of white spruce (Picea Glauca) to experimental warming at a subarctic alpine treeline, Global Change Biol., 13, 437-451, 2007.

Etzelmüller, B., Farbrot, H., Gudmundsson, A., Humlum, O., Tveito, O. E., and Björnsson, H.: The regional distribution of mountain permafrost in Iceland, Permafrost Periglac., 18, 185199, 2007.

Etzelmüller, B., Schuler, T. V., Isaksen, K., Christiansen, H. H., Farbrot, H., and Benestad, R.: Modeling the temperature evolution of Svalbard permafrost during the 20th and 21st century, The Cryosphere, 5, 67-79, doi:10.5194/tc-5-67-2011, 2011.

Föhn, P. and Meister, R.: Distribution of snow drifts on ridge slope: measurements and theoretical approximations, Ann. Glaciol., 4, 52-57, 1983 .

Farbrot, H., Etzelmüller, B., Schuler, T. V., Gudmundsson, A., Eiken, T., Humlum, O., and Björnsson, H.: Thermal characteristics and impact of climate change on mountain permafrost in Iceland, J. Geophys. Res., 112, F03S90, doi:10.1029/2006JF000541, 2007.

Gorbunov, A. P., Marchenko, S. S., and Seversky, E. V.: The thermal environment of blocky materials in the mountains of Central Asia, Permafrost Periglac., 15, 95-98, 2004.

Gruber, S.: Mountain permafrost: Transient spatial modelling, model verification and the use of remote sensing, Ph.D. thesis, University of Zurich, 2005.

Gruber, S. and Haeberli, W.: Permafrost in steep bedrock slopes and its temperature-related destabilization following climate change, J. Geophys. Res., 112, F02S18, doi:10.1029/2006JF000547, 2007.

Gruber, S. and Hoelzle, M.: Statistical Modelling of Mountain Permafrost Distribution: Local Calibration and Incorporation of Remotely Sensed Data, Permafrost Periglac., 12, 69-77, doi:10.1002/ppp 374, 2001.

Gruber, S. and Hoelzle, M.: The cooling effect of coarse blocks revisited: a modeling study of a purely conductive mechanism, in: 9th International Conference on Permafrost, 2008.

Gruber, S., Peter, M., Hoelzle, M., Woodhatch, I., and Haeberli, W.: Surface Temperatures in steep alpine rock faces - a strategy for regional-scale measurement and modelling, in: Proceedings of the 8th International Conference on Permafrost, 2003.

Gruber, S., Hoelzle, M., and Haeberli, W.: Permafrost thaw and destabilization of Alpine rock walls in the hot summer of 2003, 
Geophys. Res. Lett., 31, L13504, doi:10.1029/2004GL020051, 2004a.

Gruber, S., King, L., Kohl, T., Herz, T., Haeberli, W., and Hoelzle, M.: Interpretation of Geothermal Profiles Perturbed by topography: the alpine permafrost boreholes at Stockhorn plateau, Switzerland, Permafrost Periglac., 15, 349-357, 2004b.

Grünewald, T., Schirmer, M., Mott, R., and Lehning, M.: Spatial and temporal variability of snow depth and ablation rates in a small mountain catchment, The Cryosphere, 4, 215-225, doi:10.5194/tc-4-215-2010, 2010.

Gupta, H. V., Beven, K., and Wagener, T.: Model calibration and uncertainty estimation, 2005.

Haeberli, W.: Die Basis-Temperatur der winterlichen Schneedecke als möglicher Indikator für die Verbreitung von Permafrost in den Alpen, Zeitschrift für Gletscherkunde und Glaziologie, 9, 221-227, 1973.

Haeberli, W.: Untersuchung zur Verbreitung von Permafrost zwischen Flüelapass und Piz Grialetsch (Graubünden), Ph.D. thesis, Universitiy of Basel, 1975.

Harris, S. A.: Lower mean annual ground temperature beneath a block stream in the Kunlun Pass, Qinghai Province, China, 1996.

Harris, S. A., Cheng, G., Zhao, X., and Yongqin, D.: Nature and Dynamics of an Active Block Stream, Kunlun Pass, Qinghai Province, People's Republic of China, Geogr. Ann. A, 80, 123 133, 1998.

Harris, C., Arenson, L. U., Christiansen, H. H., Etzelmüller, B., Frauenfelder, R., Gruber, S., Haeberli, W., Hauck, C., Hölzle, M., Humlum, O., Isaksen, K., Kääb, A., Kern-Lötschg, M. A., Lehning, M., Matsuoka, N., Murton, J. B., Nötzli, J., Phillips, M., Ross, N., Seppälä, M., Springman, S. M., and Vonder Mühll, D.: Permafrost and climate in Europe: Monitoring and modelling thermal, geomorphological and geotechnical responses, Earth-Sci. Rev., 92, 117-171, doi:10.1016/j.earscirev.2008.12. 002, 2009.

Hauck, C., Isaksen, K., Vonder Mühll, D., and Sollid, J. L.: Geophysical Surveys Designed to Delineate the Altitudinal Limit of Mountain Permafrost: an Example from Jotunheimen, Norway, Permafrost Periglac., 15, 191-205, 2004.

Heggem, E. S. F., Etzelmüller, B., Anarmaa, S., Sharkhuu, N., Goulden, C. E., and Nandinsetseg, B.: Spatial distribution of ground surface temperatures and active layer depths in the Hövsgöl area, northern Mongolia, Permafrost Periglac., 17, 357369, doi:10.1002/ppp.568, 2006.

Hipp, T., Etzelmüller, B., Farbrot, H., and Schuler, T. V.: Modelling the temperature evolution of permafrost and seasonal frost in southern Norway during the 20th and 21st century, The Cryosphere Discuss., 5, 811-854, doi:10.5194/tcd-5-811-2011, 2011.

Hoelzle, M.: Permafrost occurrence from BTS measurements and climatic parameters in the Eastern Swiss Alps, Permafrost Periglac., 3, 143-147, 1992.

Hoelzle, M. and Gruber, S.: Borehole and ground surface temperatures and their relationship to meteorological conditions in the Swiss alps, in: 9th International Conference on Permafrost, 2008.

Hoelzle, M., Vonder Mühll, D., and Haeberli, W.: Thirty years of permafrost research in the Corvatsch-Furtschellas area, Eastern Swiss Alps: a review, Norsk Geogr. Tidsskr., 56, 137-145, 2002. Hoelzle, M., Haeberli, W., and Mittaz, C.: Miniature ground tem- perature data logger measurements 2000-2002 in the MurtèlCorvatsch area, Eastern Swiss alps, in: 8th International Conference on Permafrost, Proceedings, edited by: Phillips, M., Springman, S., and Arenson, L., 419-424, Swets \& Zeitlinger: Lisse, Zürich, 2003.

Isaksen, K., Hauck, C., Gudevang, E., and Oedegaard, R. S.: Mountain permafrost distribution in Dovrefjell and Jotunheimen, southern Norway, based on BTS measurements and 2D tomography data, Norsk Geogr. Tidsskr., 56, 122-136, 2002.

Ishikiwa, M. and Hirakawa, K.: Mountain permafrost distribution based on BTS measurements and DC resistivity soundings in the Daisetsu Mountains, Hokkaido, Japan, Permafrost Periglac., 11, 109-123, 2000.

Juliussen, H. and Humlum, O.: Thermal regime of openwork block fields on the mountains Elaahogna and Solen, central-eastern Norway, Permafrost Periglac., 19, 1-18, doi:10.1002/ppp.607, 2008.

Keller, F.: Automated mapping of mountain permafrost using the program PERMAKART within the Geographical Information System ARC/INFO, Permafrost Periglac., 3, 133-138, 1992.

Keller, F. and Gubler, H. U.: Interaction between snow cover and high mountain permafrost, Murtèl-Corvatsch, Swiss Alps, in: Proceedings VI. International Conference on Permafrost, Beijing, South China University of Technology Press., 1993.

Keller, M., Hungerbühler, G., Knecht, O., Skeikh, S., Beutel, J., Gubler, S., Fiddes, J., and Gruber, S.: iAssist: Rapid Deployment and Maintenance of Tiny Sensing Systems, 2010.

Lewkowicz, A. G.: Evaluation of Miniature Temperature-loggers to Monitor Snowpack Evolution at Mountain Permafrost Sites, Northwestern Canada, Permafrost Periglac., 19, 323-331, 2008.

Lewkowicz, A. G. and Bonnaventure, P. B.: Equivalent Elevation: A New Method to Incorporate Variable Surface Lapse Rates into Mountain Permafrost Modelling, Permafrost Periglac., 22, doi:10.1002/ppp.720, 2011.

Luetschg, M., Lehning, M., and Haeberli, W.: A sensitivity study of factors influencing warm/thin permafrost in the Swiss Alps, J. Glaciol., 54, 696-704, 2008.

Nelson, F. E., Hinkel, K. M., Shiklomanov, N. I., Mueller, G. R., Miller, L. L., and Walker, D. A.: Active-layes thickness in north central Alaska: Systematic sampling, scale, and spatial autocorrelation, J. Geophys. Res., 103, 28963-28973, 1998.

Nötzli, J., Gruber, S., Kohl, T., Salzmann, N., and Haeberli, W.: Three-dimensional distribution and evolution of permafrost temperatures in idealized high-mountain topography, J. Geophys. Res., 112, F02S13, doi:10.1029/2006JF000545, 2007.

Oliver, M. A. and Webster, M.: Combining Nested and Linear Sampling for Determining the Scale and Form of Spatial Variation of Regionalized Variables, Geogr. Anal., 18, 227-242, 1986.

PERMOS: Permafrost in Switzerland 2006/2007, in: Glaciological Report (Permafrost) No. 8/9 of the Cryospheric Commission of the Swiss Academy of Sciences, edited by: Nötzli, J. and Vonder Mühll, D., 2010.

Powell, W. G., Chapman, D. S., Balling, N., and Beck, A. E.: Handbook of terrestrial heat-flow density determination: with guidelines and recommendations of the International Heat Flow Commission, chap. Continental heat-flow density, 167-222, Kluwer Academic Publishing, 1988.

R Development Core Team: R: A language and environment for statistical computing, R Foundation for Statistical Computing, 
ISBN 3-900051-07-0, 2011.

Rolland, C.: Spatial and seasonal variations of air temperature lapse rates in alpine regions, J. Climate, 16, 1032-1046, 2002.

Schwarb, M., Frei, C., Schär, C., and Daly, C.: Mean annual precipitation throughout the European Alps 1971-1990, 2000.

Stocker-Mittaz, C., Hoelzle, M., and Haeberli, W.: Modelling alpine permafrost distribution based on energy-balance data: a first step, Permafrost Periglac., 13, 271-282, 2002.
Šafanda, J.: Ground surface temperature as a function of the slope angle, Tectonophysics, 360, 367-375, 1999.

Zhang, T.: Influence of the seasonal snow cover in the ground thermal regime: An overview, Rev. Geophys., 43, doi:10.1029/2004RG000157, 2005.

Zhang, Y., Chen, W., and Cihlar, J.: A process-based model for quantifying the impact of climate change on permafrost thermal regimes, J. Geophys. Res., 108, doi:10.1029/2002JD003354, 2003. 